\title{
Perioperative Antidepressant Use Improves Body Image to a Greater Extent Compared to Those Not Taking Antidepressants in Patients Who Undergo Bariatric Surgery
}

\author{
David Fipps ${ }^{1} \odot$, Sharon Holder ${ }^{2}$, Dorothy Schmalz ${ }^{3}$, John Scott ${ }^{4} \odot$
}

\begin{abstract}
Introduction: Body image often improves after bariatric surgery; however, those who are depressed are more vulnerable to continuing to have body image concerns. Body image dissatisfaction and depression are associated with poorer quality of life, less weight loss after surgery, and poorer overall physical/mental functioning. Our study aims to determine whether antidepressants influence the improvement seen in body image after bariatric surgery.

Materials and methods: Body-Esteem Scale for Adolescents and Adults (BESAA), a validated tool for trending body image, was administered preoperatively and at 3, 6, and 12 months postoperative follow-ups. Scores were compared for improvement, and linear regression models were used to determine the influence of medications and demographic factors on score improvement.

Results: The study sample was consisted of 47 men and 57 women (22-72 years of age). Preoperative BMI was in the range of 35.87-75.66 (mean: 49.26). Sixty-nine percent (69\%) were taking psychiatric medications and $57 \%$ of those medications were antidepressants (12 different antidepressants represented). Improvement in BMI was in the range of 1.44-30.77 points (mean: 15.08). The majority (98.07\%) showed improved BESAA scores; two factors revealed statistical significance for influence on score magnitude. For every 1 point of BMI improvement, our sample increased BESAA scores by 0.68 points $(p=0.021)$. Those taking antidepressants scored an average of 8.55 points higher than those not taking antidepressants $(p=0.032)$. There were no significant differences found for age, gender, race, type of surgery, use of anxiolytics/hypnotics, or stimulants.

Conclusion: Perioperative antidepressant usage is associated with a greater improvement in body image after bariatric surgery compared to those who are not taking antidepressants. Given the high comorbidity of depression in bariatric surgery patients, this highlights potential for improved outcomes with treatment of psychiatric comorbidities in this population.

Keywords: Antidepressant, Bariatric surgery, Body image.

World Journal of Laparoscopic Surgery (2021): 10.5005/jp-journals-10033-1452
\end{abstract}

\section{INTRODUCTION}

Body image is defined as an individual's beliefs, emotions, behaviors, cognitions, and perceptions pertaining to his or her physical appearance.' Body image is a multifaceted psychosocial construct that forms how we picture our own body in our minds. ${ }^{2}$ There are many factors that contribute to one's perception of body image, including societal norms, self-esteem, perfectionism, physical characteristics, interpersonal experiences, and history of depression. ${ }^{1,3,4}$ The desire to improve appearance and body image is often reported as being among the most important motives for pursuing bariatric surgery. $2,5,6$ Overall, findings from both cross-sectional and longitudinal studies suggest that, in general, body image will improve after bariatric surgery, and this will often correlate to the improvement seen in the body mass index (BMI). ${ }^{7}$ However, there are still some individuals who continue to feel dissatisfied with their body image despite appropriate weight loss after bariatric surgery. ${ }^{7-9} \mathrm{~A}$ study by Pona et al. found that bariatric surgery candidates who have a history of psychopathology and other psychological risk factors may be more vulnerable to body image concerns after surgery. ${ }^{10}$ Specifically, individuals with poorer body image have been found to have a higher likelihood of depression and depressive symptoms. ${ }^{11,12}$

It has been estimated that $25-30 \%$ of bariatric surgery patients report clinically significant depression that has been found to be higher than nonsurgery-seeking adults with morbid obesity in the
1Department of Psychiatry and Psychology, Mayo Clinic, Rochester, Minnesota, United States

${ }^{2}$ Department of Psychiatry, Executive Director of the Comprehensive Outreach Research and Education (CORE) Institute, Charleston, South Carolina, United States

${ }^{3}$ Department of Parks, Recreation, and Tourism, University of Utah, Salt Lake City, Utah, United States

${ }^{4}$ Department of Surgery, Division of Minimal Access and Bariatric Surgery, University of South Carolina, Greenville, South Carolina, United States

Corresponding Author: David Fipps, Department of Psychiatry and Psychology, Mayo Clinic, Rochester, Minnesota, United States, e-mail: dfipps123@gmail.com

How to cite this article: Fipps D, Holder S, Schmalz D, et al. Perioperative Antidepressant Use Improves Body Image to a Greater Extent Compared to Those Not Taking Antidepressants in Patients Who Undergo Bariatric Surgery. World J Lap Surg 2021;14(2):126-130.

Source of support: Nil

Conflict of interest: None

general population. ${ }^{8,13-17}$ Nearly $40 \%$ of bariatric surgery candidates are taking psychotropic medications, and antidepressants are the

(c) Jaypee Brothers Medical Publishers. 2021 Open Access This article is distributed under the terms of the Creative Commons Attribution 4.0 International License (https://creativecommons.org/licenses/by-nc/4.0/), which permits unrestricted use, distribution, and non-commercial reproduction in any medium, provided you give appropriate credit to the original author(s) and the source, provide a link to the Creative Commons license, and indicate if changes were made. The Creative Commons Public Domain Dedication waiver (http://creativecommons.org/publicdomain/zero/1.0/) applies to the data made available in this article, unless otherwise stated. 
most frequently prescribed..$^{18}$ Furthermore, patients concerned with their body image were more likely to be taking psychotropic medications and to be involved in outpatient therapy..$^{10}$ Depression alone has been shown to increase the risk of diabetes 1.4 -fold, ${ }^{19}$ coronary artery disease 1.5 - to 2 -fold, ${ }^{20}$ and stroke 1.8 -fold. ${ }^{21}$ However, body image dissatisfaction and depression can further worsen weight loss efforts causing one to feel self-conscious while engaging in physical activity and even doubt one's likelihood of successfully losing weight, which in turn can hinder healthy eating habits and behavioral changes. ${ }^{8,22}$ Similarly, body image dissatisfaction and depression in postbariatric patients are associated with less weight loss ${ }^{23}$ and can result in regaining of the weight that was lost, nutritional deficiencies, and even increased risk of death. ${ }^{24,25}$

Considering these findings authors suggest that body image should be considered an outcome parameter in assessing health-related quality of life in patients undergoing bariatric surgery. ${ }^{23,26}$ It has also been noted that further study to find interventions that increase body satisfaction would be of great value to the field. ${ }^{23}$ In this context, this study aims to determine what factors have the greatest influence on the magnitude of body image improvement postbariatric surgery with a particular focus on perioperative antidepressant usage.

\section{Materials and Methods}

This study was approved via the institutional review board of an academic tertiary care center. Patients who had been approved for bariatric surgery were consecutively recruited and consented by the attending surgeon of record. Inclusion criteria for the study are patients must be aged 18 years or older with a BMI $\geq 35$ and opting to undergo any type of bariatric surgery. There were no unique factors for exclusion not identified by the inclusion criteria. Those who consented to participate in the study completed a battery of self-administered questionnaires, including a validated metric for trending perceived body image (also termed "body esteem"). These questionnaires were administered by office-based psychologists and dieticians at four time intervals: approximately 1 month prior to surgery and then at 3, 6, and 12 months postoperatively (in tandem with the pre- and postoperative outpatient visits).

The scale that was used to assess trends in body image was the Body-Esteem Scale for Adolescents and Adults (BESAA) a commonly used validated metric for assessing body image and confidence in both psychological and bariatric surgery literature. ${ }^{27-29}$ The BESAA is a 22-item questionnaire with scores of 1, 2, 3, 4, and 5 points corresponding answers of "never," "rarely," "sometimes," "often," and "always," respectively. A higher score on the BESAA indicates higher overall body esteem and confidence regarding one's body image. The BESAA scores were compiled at each of the collection time points noted earlier and the presurgical score was compared to the score at the final follow-up appointment. Summary and descriptive statistics were generated for all patients regarding sociodemographic, surgical, and psychiatric characteristics (Table 1).

Linear regression models were employed to assess the relationship between the improvement seen in the BESAA scores and the demographic factors listed in the descriptive statistics table. Results of the linear regression analysis are displayed as coefficients where a positive coefficient indicates a positive influence on the BESAA trend, and a negative coefficient indicates a

\begin{tabular}{|c|c|}
\hline Characteristic & $N=104$ \\
\hline Age distribution & $\begin{array}{c}\text { Range: } 22-72 \\
\text { Mean: } 44.28\end{array}$ \\
\hline $20-29$ & $2.70 \%$ \\
\hline $30-39$ & $22.22 \%$ \\
\hline $40-49$ & $30.16 \%$ \\
\hline $50-59$ & $20.63 \%$ \\
\hline $60-69$ & $12.70 \%$ \\
\hline$\geq 70$ & $1.59 \%$ \\
\hline \multicolumn{2}{|l|}{ Sex } \\
\hline Male & $45.2 \%$ \\
\hline Female & $54.8 \%$ \\
\hline \multicolumn{2}{|l|}{ Race/ethnicity } \\
\hline Caucasian & $50.96 \%$ \\
\hline African American & $18.50 \%$ \\
\hline Hispanic American & $10.10 \%$ \\
\hline Asian American & $9.03 \%$ \\
\hline Prefer not to respond & $11.41 \%$ \\
\hline Preoperative BMI & $\begin{array}{l}\text { Range: } 35.87-75.66 \\
\text { Mean: } 49.26\end{array}$ \\
\hline $35-39.99$ & $9.09 \%$ \\
\hline $40-49.99$ & $53.25 \%$ \\
\hline $50-59.99$ & $25.97 \%$ \\
\hline $60-69.99$ & $7.79 \%$ \\
\hline$\geq 70$ & $3.90 \%$ \\
\hline Postoperative BMI improvement & $\begin{array}{l}\text { Range: } 1.44-30.77 \\
\text { Mean: } 15.08\end{array}$ \\
\hline$<10$ & $16.8 \%$ \\
\hline 10-19.99 & $66.23 \%$ \\
\hline 20-29.99 & $15.58 \%$ \\
\hline$\geq 30$ & $1.29 \%$ \\
\hline \multicolumn{2}{|l|}{ Surgical procedure } \\
\hline Roux-en-Y gastric bypass & $53.65 \%$ \\
\hline Vertical sleeve gastrectomy & $46.35 \%$ \\
\hline \multicolumn{2}{|l|}{ Psychiatric medications } \\
\hline Not on psychiatric medications & $31.55 \%$ \\
\hline On psychiatric medications & $68.45 \%$ \\
\hline Antidepressants & $57.01 \%$ \\
\hline Anxiolytic/hypnotic & $25.59 \%$ \\
\hline Stimulant & $2.74 \%$ \\
\hline
\end{tabular}

BMI, body mass index

negative influence on the BESAA trend. The numerical value of the coefficient indicates the number of average points of influence seen by that variable (e.g., a positive 4-point coefficient would indicate, on average, those with the demographic variable had an average of four points higher on the BESAA scores than those without the demographic variable). For nonbinary variables like postoperative improvement in $\mathrm{BMI}$, the coefficient indicates the influence on the BESAA score per 1 point of BMI improvement. Levels of significance were assessed using $t$-test of regression coefficients. $p$-values less 
than 0.05 were considered indicative of statistical significance. Data were analyzed using $\mathrm{R}$ statistical software via the R Foundation for Statistical Computing 2017 (version 3.43, Vienna, Austria).

\section{Results}

The study sample included 47 men and 57 women ranging from 22 to 72 years of age (mean age 44.28 years). Preoperative BMI ranged from 35.87 to 75.66 (mean BMI 49.26). Over $72 \%$ (72.63\%) provided comparison information for 3 months, $(75.78 \%)$ 6 months, and (63.15\%) 12 months. Sixty-nine percent $(69 \%)$ of our samples were taking psychiatric medications, and $57 \%$ of those medications were antidepressants. Represented antidepressants in our sample included: amitriptyline (5), bupropion (10), citalopram (34), duloxetine (4), escitalopram (9), fluoxetine (6), nortriptyline (1), paroxetine (3), sertraline (4), venlafaxine (1), vilazodone (4), and vortioxetine (3). Noted 35 patients were on $>1$ psychotropic medication and 9 of those patients were on $>1$ antidepressant. Fifty-three percent (53.65\%) underwent Roux-en-Y gastric bypass and (46.35\%) underwent vertical sleeve gastrectomy. The improvement in BMI ranged from 1.44 points to 30.77 points (average of $15.08 \mathrm{BMI}$ improvement points). For further details of these patient demographics, see Table 1.

The majority $(98.07 \%)$ of our patient sample demonstrated improved scores on the BESAA metrics and two factors revealed statistical significance regarding the influence of score magnitude. The first factor, as expected, was BMI improvement demonstrating a coefficient of $0.684(p=0.021)$. Hence, for every 1 point of BMI improvement, our sample increased their BESAA scores by 0.68 points. The second factor of statistical significance was perioperative antidepressant use with a coefficient of $8.556(p=0.032)$. Hence, those in our sample who were taking an antidepressant scored an average of 8.55 points higher on the BESAA scores than those who were not taking an antidepressant. There were no significant differences found regarding the influence on the BESAA scores in age, gender, race, type of surgery, use of anxiolytics/hypnotics, or stimulants (Table 2). We excluded education and employment status due to the lack of patient responses on these surveys.

Table 2: Linear regression for demographic influence on body image improvement

\begin{tabular}{lcl}
\hline Demographic characteristics & Coefficient & $p$-value \\
\hline Age & 0.039 & 0.784 \\
Sex & & \\
Male* & 1.00 & 1.00 \\
Female & -4.726 & 0.266 \\
Race/ethnicity & & \\
Caucasian* & 1.00 & 1.00 \\
Non-Caucasian & 4.988 & 0.154 \\
Postoperative BMI improvement & 0.684 & $0.021 * *$ \\
Surgical procedure & & \\
Roux-en-Y gastric bypass* & 1.00 & 1.00 \\
Vertical sleeve gastrectomy & 0.039 & 0.822 \\
Psychiatric medications & & \\
Antidepressant & 8.556 & $0.032 * *$ \\
Anxiolytic/hypnotic & 0.993 & 0.743 \\
Stimulant & 4.993 & 0.366 \\
\hline *Reference groups; **Statistically significant level: $p<0.05 ; \mathrm{BMI}$, body \\
mass index
\end{tabular}

\section{Discussion}

Our study results indicate that the majority of patients who undergo bariatric surgery will see an improvement in their body image, and the magnitude to which this improvement is seen is influenced by the improvement in the BMI and being on an antidepressant. Specifically for every 1 point of BMI improvement, our sample increased their body image scores by 0.68 points, $(p=0.021)$ and those who were taking an antidepressant scored an average of 8.55 points higher on the body image scores than those who were not taking an antidepressant $(p=0.032)$. The results of our study reflect similar concepts found in the literature. Overall, there are significant improvements seen in body image following bariatric surgery, and these improvements often correlate with the percentage of weight loss and can similarly decompensate if weight is regained. ${ }^{2,7-9,30-37}$ In addition, there are multiple studies demonstrating that treating a psychiatric comorbidity can result in more favorable "nonpsychiatric" outcomes. For example, a recent randomized controlled trial (RCT) showed that congestive heart failure patients who achieved clinical remission of depression demonstrated a statistically significant reduction in cardiovascular events compared to the nonremission group. ${ }^{38}$ In another RCT, patients with breast cancer undergoing adjuvant hormonal therapy, local radiation, and/or adjuvant chemotherapy reported that antidepressant treatment reduced depressive symptoms, improved quality of life, and increased the likelihood of completion of adjuvant treatment vs the placebo group. ${ }^{39}$ Considering the high prevalence of depression in the bariatric surgery population, it is understandable that a treatment for depression could produce a more favorable outlook on one's body image. This trend has been seen with psychotherapeutic interventions perioperatively. For example, cognitive behavioral therapy (CBT) was shown to improve distress related to body image as well as reported self-esteem and depression symptoms. ${ }^{40-42}$ In addition, acceptance and commitment therapy demonstrated significant improvements in body image and weight concerns compared to treatment as usual. $7,43,44$

Body image dissatisfaction and depression not only act as single factors that can impede success in a patient's weight loss journey but also interact with each other in a bidirectional manner. ${ }^{11,12}$ In fact, poor body image has been proposed to mediate the relationship between obesity and psychological symptoms of depression and low self-esteem. ${ }^{45}$ Bodily dissatisfaction and psychological distress can act as a trigger for stress-related eating behaviors. ${ }^{46}$ In addition, among individuals seeking bariatric surgery, body image dissatisfaction was associated with binge eating, depression, and lower self-esteem., ${ }^{7,47}$ The literature also suggests that if a patient is not prepared psychologically for body image challenges after bariatric surgery, there is a higher likelihood of experiencing disturbed body image postoperatively. ${ }^{48}$ As mentioned earlier, depression has been shown to increase the risk of diabetes 1.4 -fold ${ }^{19}$ coronary artery disease 1.5 - to 2 -fold ${ }^{20}$ and stroke 1.8 -fold, ${ }^{21}$ to name a few. These risk increases are likely mediated by both biological mechanisms and unhealthy behaviors related to poor self-care, diet, exercise, and treatment adherence, thereby contributing to increased morbidity and mortality. ${ }^{49}$ In fact, comorbid depression is associated with a 3-fold greater risk of nonadherence to medical treatment ranging from medication nonadherence to missing appointments to not following diet, exercise, or lifestyle recommendations. ${ }^{50}$ Studies show that this increased mortality rate persists even after confounding factors 
are controlled for: such as smoking, disease severity, and alcohol consumption. ${ }^{51,52}$

Employing strategies targeted to improve body image and appropriately treat psychiatric comorbidities could lead to more improvements in bariatric surgery outcomes. Though recent literature indicates that simply being on an antidepressant does not directly affect the amount of weight loss 1 year after gastric bypass surgery, ${ }^{53}$ weight loss cannot be considered the only outcome of focus. Improvement in body image after bariatric surgery is associated with notable improvements in physical and mental quality of life. ${ }^{32,36}$ In addition, studies have demonstrated both sexual and psychological functional improvements after bariatric surgery correlated to improved body image metrics. ${ }^{54}$ Furthermore, body image satisfaction is associated with less depressive symptoms in postbariatric patients. ${ }^{23}$ To that end, appropriately treated depression can represent an opportunity to further improve the patient's quality of life, decrease the patient's risk for suicide, and improve overall treatment compliance.

\section{LiMITATIONS}

To begin, we systematically explored a relatively large number of explanatory variables with a sample of modest size; therefore, we may not have had sufficient power to detect associations between some demographic characteristics such as other medial comorbidities, employment status, and level of education. Second, self-reporting conditions might underestimate their prevalence. Third, expanding the perioperative evaluation to include postoperative PHQ-9s as well as anxiety screens (GAD-7s) would have provided a helpful tool for trending symptomatic changes in the patients' depression and anxiety. Fourth, this study focused on simply being on an antidepressant and not if the medication dosing was fully optimized to efficacious dosing. As some patients were underdosed according to typical efficacious dosing ranges, there could be potential for an even greater magnitude of improvement if all doses were optimized. This brings about multiple points to incorporate into future prospective studies of similar focus. In addition, future studies could also incorporate the effectiveness of a combination of psychotherapy and antidepressant medication vs therapy alone and antidepressants alone on body image after bariatric surgery.

\section{Conclusion}

Perioperative antidepressant usage is associated with a greater improvement in perception of body image after bariatric surgery compared to those who are not on antidepressants. Given the high comorbidity of depression in those who undergo bariatric surgery, this highlights the potential for improved outcomes with the treatment of psychiatric comorbidities in this population.

\section{ORCID}

David Fipps (1) https://orcid.org/0000-0001-5758-704X

John Scott 마 https://orcid.org/0000-0002-5619-7637

\section{References}

1. Cash TF. The body image workbook: an eight-step program for learning to like your looks. 2nd ed. Oakland: New Harbinger; 2008.

2. Varns J, Fish A, Eagon JC. Conceptualization of body image in the bariatric surgery patient. Appl Nurs Res 2018;41:52-58. DOI: 10.1016/ j.apnr.2018.03.008,
3. Cash TF. Cognitive behavioral perspectives on body image. In: Cash TF, Smolak L, editors. Body image: a handbook of science, practice, and prevention. 2nd ed. New York: The Guilford Press; 2011. p. 39-47.

4. Bianciardi E, Lorenzo G, Niolu C, et al. Body Image dissatisfaction in individuals with obesity seeking bariatric surgery: exploring the burden of new mediating factors. Riv Psichiatr 2019;54(1):8-17. DOI: $10.1708 / 3104.30935$.

5. Levy AS, Heaton AW. Weight control practices of US adults trying to lose weight, Ann Intern Med 1993;119(7 Pt 2):661-666. DOI: 10.7326/0003-4819-119-7_part_2-199310011-00007.

6. Libeton M, Dixon JB, Laurie C, et al. Patient motivation for bariatric surgery: characteristics and impact on outcomes. Obesity Surg 2004;14(3):392-398. DOI: 10.1381/096089204322917936.

7. Ivezaj V, Grilo C. The complexity of body image following bariatric surgery: a systematic review of the literature. Obes Rev 2018;19(8):1116-1140. DOI: 10.1111/obr.12685.

8. Sarwer DB, Wadden TA, Fabricatore AN. Psychosocial and behavioral aspects of bariatric surgery. Obes Res 2005;13(4):639-648. DOI: $10.1038 / o b y .2005 .71$.

9. Neven K, Dymek M, leGrange D, et al. The effects of Roux-en-Y gastric bypass surgery on body image. Obes Surg 2002;12(2):265-269. DOI: $10.1381 / 096089202762552755$.

10. Pona AA, Heinberg LJ, Lavery $M$, et al. Psychological predictors of body image concerns 3 months after bariatric surgery. Surg Obes Relat Dis 2016;12(1):188-193. DOI: 10.1016/j.soard.2015.05.008.

11. Van Eck K, Morse M, Flory K. The role of body image in the link between ADHD and depression symptoms among college students. J Atten Disord 2015;22(5). DOI: 10.1177/1087054715580845.

12. Jackson KL, Janssen I, Appelhans BM, et al. Body image satisfaction and depression in midlife women: the study of women's health across the nation (SWAN). Arch Women's Ment Health 2014;17(3):177-187. DOI: 10.1007/s00737-014-0416-9.

13. de Zwaan M, Georgiadou E, Stroh CE, et al. Body image and quality of life in patients with and without body contouring surgery following bariatric surgery: a comparison of pre- and post-surgery groups. Front Psychol 2014;5:1310. DOI: 10.3389/fpsyg.2014.01310.

14. Sarwer DB, Cohn NI, Gibbons LM, et al. Psychiatric diagnoses and psychiatric treatment among bariatric surgery candidates. Obes Surg 2004;14(9):1148-1156. DOI: 10.1381/0960892042386922.

15. Sarwer DB, Thompson JK, Cash TF. Body image and obesity in adulthood. Psychiat Clin N Am 2005;28(1):69-87. DOI: 10.1016 /j.psc.2004.09.002.

16. Rand CS, Kuldau JM. Morbid obesity: a comparison between a general population and obesity surgery patients. Int J Obes Relat Metab Disord 1993;17(11):657-661. PMID: 8281224.

17. Williams G, Hudson D, Whisenhunt B, et al. Short-term changes in affective, behavioral, and cognitive components of body image after bariatric surgery. Surg Obes Relat Dis 2018;14(4):521-526. DOI: 10.1016/j.soard.2017.12.026.

18. Levenson JL. The APA textbook of psychosomatic medicine and consultation Liaison psychiatry. 3rd ed. Washington DC: American Psychiatric Association Publishing; 2019.

19. Yu M, Zhang X, Lu F, et al. Depression and risk for diabetes: a meta-analysis. Can J Diab 2015;39(4):266-272. DOI: 10.1016/ j.jcjd.2014.11.006.

20. Van der Kooy K, van Hout $\mathrm{H}$, Marwijk H, et al. Depression and the risk for cardiovascular diseases: systematic review and meta-analysis. Int J Geriatr Psychiatry 2007;22(7):613-626. DOI: 10.1002/gps.1723.

21. Ramasubbu R, Patten S. Effect of depression on stroke morbidity and mortality. Can J Psychiatry 2003;48(4):250-257. DOI: $10.1177 / 070674370304800409$.

22. Schwartz MB, Brownell KD. Obesity and body image. Body Image 2004;1(1):43-56. DOI: 10.1016/S1740-1445(03)00007-X.

23. Monpellier VM, Antoniou E, Mulkens S, et al. Body image dissatisfaction and depression in postbariatric patients is associated with less weight loss and a desire for body contouring surgery. Surg Obes Relate Dis 2018;14(10):1507-1515. DOI: 10.1016/j.soard.2018.04.016. 
24. McCabe MP, Ricciardelli LA. Body image dissatisfaction among males across the lifespan: a review of past literature. J Psychosom Res 2004;56(6):675-685. DOI: 10.1016/S0022-3999(03)00129-6.

25. Lacerda RM, Castanha CR, Castanha AR, et al. Perception of body image by patients undergoing bariatric surgery. Rev Col Bras Cir 2018;45(2):e1793. DOI: 10.1590/0100-6991e-20181793.

26. Yusufov $M$, Dalrymple $K$, Berstein $M$, et al. Body mass index, depression, and suicidality: the role of self-esteem in bariatric surgery candidates. J Affective Disord 2017;208:328-347. DOI: 10.1016/ j.jad.2016.10.005.

27. Mendelson $B$, White $D$. Body-esteem scale for adolescents and adults. J Person Assess 2001;76(1):90-106. DOI: 10.1207/S15327752JPA7601_6.

28. Madan AK, Beech BM, Tichansky DS. Body esteem improves after bariatric surgery. Surg Innov 2008;15(1):32-37. DOI: 10.1177/1553350608316135.

29. Franzoi SL, Herzog ME. The body esteem scale: a convergent and discriminant validity study. J Personality Assess 1986;50(1):24-31. DOI: 10.1207/s15327752jpa5001_4.

30. Adami GF, Meneghelli A, Bressani A, Scopinaro body image in obese patients before and after stable weight reduction following bariatric surgery. J Psychosom Res 1999;46(3):275-281. DOI: 10.1016/s00223999(98)00094-4.

31. Camps MA, Zervos E, Goode $S$, et al. Impact of bariatric surgery on body image and their partners. Obes Surg 1996;6(4):356-360. DOI: 10.1381/096089296765556700.

32. Dixon JB, Dixon ME, O'Brien PE. Body image: appearance orientation and evaluation in the severely obese. Changes with weight loss. Obes Surg 2002;12(1):65-71. DOI: 10.1381/096089202321144612.

33. Hrabosky Jl, Masheb RM, White MA, et al. A prospective study of body dissatisfaction and concerns in extremely obese gastric bypass patients: 6- and 12-month postoperative outcomes. Obes Surg 2006;16(12):1615-1621. DOI: 10.1381/096089206779319527.

34. Ogden J, Clementi C, Aylwin S. The impact of obesity surgery and the paradox of control: a qualitative study. Psychol Health 2006;21(2):273293. DOI: $10.1080 / 14768320500129064$.

35. Teufel M, Rieber N, Meile T, et al. Body Image after sleeve gastrectomy: reduced dissatisfaction and increased dynamics. Obes Surg 2012;22(8):1232-1237. DOI: 10.1007/s11695-012-0690-4.

36. Sarwer DB, Wadden TA, Moore RH, et al. Williams. Changes in quality of life and body image after gastric bypass surgery. Surg Obes Relat Dis 2010;6(6):608-614. DOI: 10.1016/j.soard.2010.07.015.

37. Cash TF, Counts B, Huffine CE. Current and vestigial effects of overweight among women: fear of fat, attitudinal body image, and eating behaviors. J Psychopathol Behav Assess 1990;12(2):157-167. DOI: 10.1007/BF00960765.

38. Jiang W, Krishnan R, Kuchibhatla M, et al. SADHART-CHF Investigators: characteristics of depression remission and its relation with cardiovascular outcome among patients with chronic heart failure (from the SADHART-CHF Study). Am J Cardiol 2011;107(4):545-551. DOI: 10.1016/j.amjcard.2010.10.013.

39. Navari R, Brenner M, Wilson M. Treatment of depressive symptoms in patients with early stage breast cancer undergoing adjuvant therapy. Breast Cancer Res Treat 2008;112(1):197-201. DOI: 10.1007/ s10549-007-9841-z.
40. Bacon L, Keim NL, Van Loan, MD, et al. Evaluating a "non-diet" wellness intervention for improvement of metabolic fitness, psychological well-being and eating and activity behaviors. Int J Obes Relat Metab Disord 2002;26(6): 854-865. DOI: 10.1038/ sj.ijo.0802012.

41. Rosen JC, Orosan P, Reiter J. Cognitive behavioral therapy for negative body image in obese women. Behav Ther 1995;26(1):25-42. DOI: 10.1016/S0005-7894(05)80081-4.

42. Roughan P, Seddon E, Vernon-Roberts J. Long-term effects of a psychologically based group programme for women preoccupied with body weight and eating behavior. Int J Obes 1990;14(2):135-147. PMID: 2341222.

43. Weineland S, Arvidsson D, Kakoulidis TP, et al. Acceptance and commitment therapy for bariatric surgery patients, a pilot RCT. Obes Res Clin Pract 2012;6(1):e1-e90. DOI: 10.1016/j.orcp.2011.04.004.

44. Weineland S, Hayes SC, Dahl J. Psychological flexibility and the gains of acceptance-based treatment for post-bariatric surgery: six-month follow-up and a test of the underlying model. Clin Obes 2012;2 (1-2):15-24. DOI: 10.1111/j.1758-8111.2012.00041.x.

45. Friedman KE, Reichmann SK, Costanzo PR, et al. Weight stigmatization and ideological beliefs: relation to psychological functioning in obese adults. Obes Res 2005;13(5):907-916. DOI: 10.1038/oby.2005.105.

46. Bucchianeri MM, Neumark-Sztainer D. Body dissatisfaction: an overlooked public health concern. J Public Ment Health 2014;13(2):64-69. DOI: 10.1108/JPMH-11-2013-0071.

47. Hrabosky JI, White MA, Masheb RM, et al. Psychometric evaluation of the eating disorder examination-questionnaire for bariatric surgery candidates. Obesity (Silver Spring) 2008;16(4):763-769. DOI: 10.1038/ oby.2008.3.

48. Perdue T, Schreier A, Neil J, et al. A concept analysis of disturbed body image in bariatric surgery patients. Int J Nurs Knowl 2020;31(1):74-81. DOI: $10.1111 / 2047-3095.12220$.

49. Katon WJ. Clinical and health services relationships between major depression, depressive symptoms, and general medical illness. Biol Psychiatry 2003;54(3):216-226. DOI: 10.1016/s00063223(03)00273-7.

50. DiMatteo MR, Lepper HS, Croghan TW. Depression is a risk factor for noncompliance with medical treatment: meta-analysis of the effects of anxiety and depression on patient adherence. Arch Intern Med 2000;160(14):2101-2107. DOI: 10.1001/archinte.160.14.2101.

51. Schulz R, Beach SR, Ives DG, et al. Association between depression and mortality in older adults: the Cardiovascular Health Study. Arch Intern Med 2000;160(12):1761-1768. DOI: 10.1001/ archinte.160.12.1761.

52. Katon W, Lin E, Kroenke K. The association of depression and anxiety with medical symptom burden in patients with chronic medical illness. Gen Hosp Psychiatry 2007;29(2):147-155. DOI: 10.1016/ j.genhosppsych.2006.11.005.

53. Malone M, Alger-Mayer S, Polimeni J. Antidepressant drug therapy does not affect weight loss on year after gastric bypass surgery. Obes Surg 2011;21:1721-1723. DOI: 10.1007/s11695-010-0351-4.

54. Pujols $Y$, Seal BN, Meston CM. The association between sexual satisfaction and body image in women. J Sex Med 2010(2 Pt2): 905-916. DOI: 10.1111/j.1743-6109.2009.01604.x. 